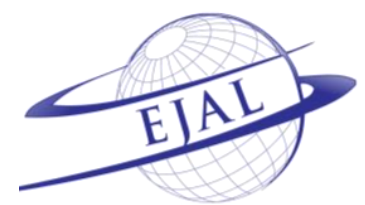

Available online at www.ejal.eu

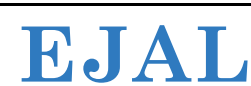

Eurasian Journal of

Eurasian Journal of Applied Linguistics 4(1) (2018) 17-25

Applied Linguistics

\title{
Iranian EFL Learners' Perception of the Importance and Frequency of Teachers' Motivational Strategies
}

\author{
Saeed Safdari a * (iD) \\ ${ }^{a}$ Department of English, Chalous Branch, Islamic Azad University, Chalous, Iran
}

Received 19 March 2017 | Received in revised form 15 December 2017 | Accepted 13 February 2018

\begin{abstract}
The purpose of this article is to study the perception of Iranian EFL learners of the importance and frequency of their teachers' motivational strategies. Preceded by a few similar studies, this research study was conducted in the cultural milieu of Iran where learners have different characteristics compared to their counterparts in other areas of the world. A total of 168 students took part in the study and completed a Likert scale questionnaire on both importance and frequency of the motivational strategies in their language classrooms. The descriptive and correlational analyses revealed that there is relative congruence between what the students regarded to be important and what their teachers performed in the classrooms. Besides, the students' choice of the strategies shows that they consider the teacher as the major model and source of confidence. The results are discussed with particular attention to the cultural context of Iran.
\end{abstract}

(C) 2018 EJAL \& the Authors. Published by Eurasian Journal of Applied Linguistics (EJAL). This is an open-access article distributed under the terms and conditions of the Creative Commons Attribution license (CC BY-NC-ND) (http://creativecommons.org/licenses/by-nc-nd/4.0/).

Keywords: L2 motivation; motivational strategies; EFL learners; EFL teacher

\section{Introduction}

Motivation has always been a significant concept in learning and teaching (Dörnyei, 1998; MacIntyre \& Blackie, 2012; Weger, 2013). Dörnyei (2001) construes it as the most complex and challenging issue which teachers should face. Motivation serves as the primary engine to generate learning. Cheng and Dörnyei (2007) believe that it "functions as an ongoing driving force that helps to sustain the long and usually laborious journey of acquiring a foreign language" (p. 15). Since Gardner and Lambert (1959) introduced the concept as a research agenda, numerous studies have confirmed the importance of motivation and its vital role in learning activities in general, and L2 acquisition in specific (Dörnyei, 1998, 2001; Oxford \& Shearin, 1994; Spolsky, 2000).

Traditionally, scholars have been concerned with what motivation is rather than how teachers can use the findings of motivational research to actually push their

\footnotetext{
* Saeed Safdari. Tel.: +98-911-195-9246

E-mail address: saeed_safdari@yahoo.com

http://dx.doi.org/.......
} 
students and motivate them. It means that they have paid more attention to theoretical aspects of motivation rather than its pedagogical application (Moskovsky, Alrabai, Paolini \& Ratcheva, 2012). The literature is replete with theories and perspectives which have attempted to define motivation as a significant construct, but much less effort has been invested to examine the effectiveness of motivational techniques and strategies in educational contexts (Dörnyei, 2007). However, more and more researchers are turning towards the pedagogical implications of research by bringing the concept of motivational strategies onto the educational stage (Alison \& Halliwell, 2002; Dörnyei, 2006; Hiromori, 2009).

Motivational strategies are techniques used by teachers to promote and maintain students' motivation to learn. They are defined as "those motivational influences that are consciously exerted to achieve some systematic and enduring positive effect" (Dörnyei, 2001, p.28). There are studies that have investigated the relationship between the use of motivational strategies by teachers and L2 learners' achievements (Bernaus \& Gardner, 2008; Bernaus, Wilson \& Gardner, 2009; Guilloteaux and Dörnyei, 2008; Papi \& Abdollahzadeh, 2011). The previous studies suggest a number of motivational strategies that should be used by language teachers, and show that the motivational strategies used by L2 teachers can increase students' motivation which leads to a positive effect on their L2 achievement.

Gardner and Tremblay (1994) casted doubt on the effectiveness of any motivational strategies and drew attention to the need for proper identification of the strategies that were actually fruitful. Dörnyei and Csizér (1998) conducted an empirical study by asking English teachers to identify the strategies that increased student motivation. Their study led to the publication of their ten commandments for motivating language learners. Later, Dörnyei (2001) continued the efforts and provided a framework of more than 100 specific motivational strategies. The strategies were divided into four stages focusing on a) creating the basic motivational conditions, b) generating initial motivation, c) maintaining and protecting motivation, and d) encouraging positive self-evaluation.

More recent developments in L2 motivation research provide ample support for the importance of teachers' motivational strategies. The theorizing of Dörnyei's (2005, 2009) tripartite model, the L2 motivational self system (L2MSS), renewed the focus on situated and contextualized aspects of language learning. According to L2MSS, one of the major underlying components of L2 learners' motivational disposition is their language learning experience. It is concerned with students' attitudes towards the immediate language learning context including the environment, teacher, tasks, materials etc. (Dörnyei, 2009). Some empirical studies found supporting evidence that classroom experience (including teacher performance) exerts a strong impact on motivated behavior (Csizér \& Kormos, 2009; Papi, 2010; Taguchi, Magid \& Papi, 2009).

Regarding the usefulness of the strategies, there still remain lots of questions to be answered. Interestingly, even Dörnyei and Csizér (1998) themselves admitted the 
importance of cultural and contextual differences and left a room for doubt on the validity of using the commandments in every cultural and institutional setting ( $p$. 224). Cheng and Dörnyei (2007) continued this assertion and emphasized the necessity of considering culture-specific variables in studying motivational strategies. They state that learners' approach to learning and teachers' ideologies "may render some techniques highly effective, while others less useful" (Cheng \& Dörnyei, 2007, p. 155). These variables play a key role in affecting participants' beliefs about the importance of motivational strategies. In addition, Guilloteaux and Dörnyei (2008) insisted that it is necessary to explore the extent to which motivational strategies are culture specific. Also, Kormos, Kiddle and Csizér (2011) believed that motivation is strongly influenced by social and contextual factors and that every cultural milieu exerts its own frameworks on motivation. This viewpoint was further corroborated by Ruesch, Bown and Dewey (2012) who stated that non-native teacher less familiar with their students' culture, may negatively affect their motivation.

\subsection{Research questions}

Some previous studies have elicited data from EFL teachers and students in Hungary (Dörnyei \& Csizér, 1998), East Asia (Cheng \& Dörnyei, 2007), and North America (Ruesch et al., 2012). A more recent study by Moskovsky et al. (2012) moved a further step forward by observing and recording the implementation of the strategies in the classroom as an addition to mere self-report questionnaires. However, no study has been found to focus on the perception and evaluation of Iranian EFL learners or teachers. Therefore, this study will address this issue by examining the importance of motivational strategies from the perspective of EFL students in Iran. In particular, the current study addresses the following research questions:

1. Is there any significant relationship between students' perception of the importance and frequency of the motivational strategies?

2. Which motivational strategies do Iranian EFL students identify as most important?

3. Which motivational strategies are perceived as frequent by Iranian EFL students?

\section{Method}

\subsection{Participants}

A number of intermediate and upper-intermediate EFL learners from five different private language institutes in Tehran were asked to participate in this study. Their proficiency levels were determined by the institutional placement tests. The sample consisted of 168 students; 57 male and 111 female. Their ages ranged from 17 to 35 $($ mean $=22.5)$. The students attended their English classes two or three times a week, depending on the institute schedule. The participants were all native speakers of 
Persian and none of them had any experience of living in an English-speaking country. Most of them $(n=104)$ were university students.

\subsection{Instrument and Procedure}

In order to investigate the research questions, a questionnaire was adapted from Cheng and Dörnyei (2007). The questionnaire consisted of two distinct parts: The first part focused on the importance of strategies and included 48 items each representing a strategy. Respondents were asked to give their responses on a scale of six options describing degrees of importance (from 'not important' through to 'very important'). The second part of the questionnaire contained the same number of items corresponding to the same strategies, but this time the options described degrees of frequency (from 'hardly ever' through to 'very often').

Having been aware of the inherent shortcoming of self-reported questionnaires that the respondents are likely to describe their behaviors in a better light, according to what they believe to be the positive or the expected answers (i.e. social desirability bias), the questionnaire instructions highlighted the fact that the information provided was confidential and anonymous. The questionnaire was given to the students in their native language (Persian) and to the teachers in English.

In order to make the data more meaningful and manageable, the questionnaire items were grouped into 10 multi-item scales. Each clustered group consisted of those items which were thought to refer to the same or similar motivational strategies. To make sure about the internal consistency of the clusters, Cronbach alpha value was calculated for each of them.

Having done that, the answers were rated according to their respective numbers; in the first part of the questionnaire, not important was rated as 1 and very important rated as 6 . In the second section, hardly ever was rated as 1 and very often was given 6 points. All intervening levels were allotted their respective numbers. Following this, the means and standard deviations were calculated for each item and then the items were ranked accordingly. Then, the scales were also ranked according to the same results. Next, the frequency and importance of the items were compared using standardized scores.

\section{Results and Discussion}

The internal consistency of the multi-item scales was estimated by computing Cronbach Alpha index for all of them. The results show that the questionnaire scales were sufficiently reliable and exceeded the minimum requirement of .60 (Pallant, 2013). Also, the means of every scale was calculated and the scales were ranked according to the obtained means. A summarized description of means and reliability estimates of the importance questionnaire is provided in Table 1. 
Table 1. Ranking of importance of motivational strategies means

\begin{tabular}{llll}
\hline rank & scales & Mean & Cronbach a \\
\hline 1 & proper teacher behavior & 5.58 & .82 \\
2 & recognizing Students' effort & 5.33 & .71 \\
3 & creating pleasant classroom climate & 5.21 & .79 \\
4 & promoting Students' self-confidence & 5.10 & .74 \\
5 & presenting tasks properly & 4.88 & .80 \\
6 & familiarizing Students with L2 values & 4.67 & .69 \\
7 & increasing learners' goal-orientedness & 4.67 & .74 \\
8 & making the learning tasks stimulating & 4.46 & .83 \\
9 & prompting Students' autonomy & 4.21 & .73 \\
10 & promoting group cohesiveness \& norms & 4.19 & .64 \\
\hline
\end{tabular}

The means and reliability estimates were calculated for the frequency questionnaire as well. The results are presented in Table 2. The lowest reliability index for the frequency questionnaire was 0.66 which still meets the minimum requirement.

Table 2. Ranking of frequency of motivational strategies means

\begin{tabular}{llll}
\hline rank & scales & mean & Cronbach a \\
\hline 1 & presenting tasks properly & 4.85 & .80 \\
2 & creating pleasant classroom climate & 4.59 & .78 \\
3 & promoting Students' self-confidence & 4.48 & .79 \\
4 & proper teacher behavior & 4.48 & .68 \\
5 & promoting group cohesiveness \& norms & 4.48 & .73 \\
6 & making the learning tasks stimulating & 4.25 & .71 \\
7 & increasing learners' goal-orientedness & 4.13 & .78 \\
8 & recognizing Students' effort & 3.99 & .80 \\
9 & familiarizing Students with L2 values & 3.23 & .80 \\
10 & prompting Students' autonomy & 3.01 & .66 \\
\hline
\end{tabular}

As it is evident from the descriptive statistics, the importance ranking shows apparent differences with the frequency ranking. However, to check the mis(matches) between the respondents' ranking of importance and frequency of motivational strategies, a Spearman rank order coefficient of correlation was computed. That was to see whether the two rankings go together and demonstrate harmony or not. As Table 3 presents, the result of the correlation analysis showed that there is a weak but significant correlation between the two rankings $(\mathrm{rho}=.38, \mathrm{p}<.05)$. The coefficient of correlation indicates that the two rankings do match with each other to a limited extent i.e. the students' perception of the importance of motivational strategies is almost congruent with their perception of the frequency of the same strategies. In fact, from the respondents' point of view, the teachers were applying the more important strategies as frequently as necessary. In fact, the teachers seem to be relying on strategies which are more important. The observed congruity between what 
students consider important and what teachers deem necessary is promising and implies that L2 learning experience could be possibly pleasant and satisfactory for the learners.

Table 3. Correlation between the students' perception of the frequency and importance of strategies

\begin{tabular}{lll}
\hline Spearman's rho & Frequency & Importance \\
\hline Frequency & - & \\
Importance & $.38^{* *}$ & - \\
\hline$* *$ Correlation is significant at the 0.01 level (2-tailed). &
\end{tabular}

A review of the results elucidates learners' preferred motivational strategies. Proper teacher behavior is seen as the most significant strategy. The respondents relied on the leadership of their teachers and regarded them as the best models. So, they anticipated their instructors to provide them with the best learning behaviors and performances. Their heavy dependence on teachers' guidance is not surprising, since in Asian cultures, learners are accustomed to following their teachers' styles and preferences.

The second most important strategy involved recognizing students' efforts. In product-oriented cultures and achievement-based educational systems it is normal that students expect the authorities to perceive their attempts and confirm that they have recognized the learners' achievements. While Dörnyei and Csizér's (1998) Hungarian study found this strategy to be among the least important ones, Cheng and Dörnyei (2007) discovered that in the Taiwanese context it was a top priority. Their findings also confirm that Asian learners need to receive extrinsic praise and admiration to keep motivated.

The third most important strategy was concerned with creating pleasant classroom climate. L2 learning experience is a decisive element in the success or failure of learners. As explained by Dörnyei $(2005,2009)$, it is one of the major factors that determines L2 motivation. Therefore, it seems quite reasonable that other similar studies (Cheng \& Dörnyei, 2007; Dörnyei \& Csizér, 1998) found remarkable reports of importance for creating pleasant atmosphere in language classrooms.

Next, students showed an interest in the strategies that increased their selfconfidence. They revealed their anticipation of receiving the confidence from their teachers. Apart from the tendency of Asian learners to receive positive feedbacks from their student, they need to be judged positively. Confident learners are those who believe in their ability and are able to persist in face of the potential hardship and difficulties. They attach great value to supportive atmosphere and anxiety-free environment.

Regarding the frequency of the motivational strategies, the respondents decided that presenting tasks properly and creating pleasant classroom climate were most widely used by the instructors. This insinuates that the teachers are more concerned with the lesson content, materials presentation and classroom activities. This can be deemed a positive aspect of their teaching style because more engaging tasks and 
friendly classroom atmosphere are essential factors in building enjoyable learning experience. Apparently, the teachers have been aware of the role of positive learning experience.

Next in ranking were promoting students' self-confidence and proper teacher behavior. It is noteworthy that although the correlation coefficient between the two rankings (i.e. importance and frequency) was modestly significant, the top strategies in both rankings demonstrate remarkable correspondence and consistency. It can be concluded that teachers and learners agree on the relative importance of various motivational strategies and follow similar patterns. Nevertheless, considering the full inventory of motivational strategies, there seem to be salient differences.

\section{Conclusion}

This study was an investigation into the Iranian EFL learners' perception of the frequency and importance of motivational strategies. The findings revealed that the learners' views were in relative agreement with the actual application of the strategies by the teachers. The results imply that L2 teachers could obtain their students' preferences and needs by conducting simple surveys or brief classroom discussions and then modify their pedagogical practices to match the necessities of the learners. Just as Kumaravadivelu (2006) insisted, practitioners must be theorizers as well. It means that teachers need to apply their global and theoretical knowledge of teaching/learning practices to the local needs of their students to attain the optimum results.

\section{References}

Alison, J., \& Halliwell, S. (2002). Challenging classes: Focus on pupil behaviour. London: Centre for Information on Language Teaching and Research.

Bernaus, M., \& Gardner, R. (2008). Teacher motivation strategies, student perceptions, student motivation, and English achievement. The Modern Language Journal, 92(1), 387401.

Bernaus, M., Wilson, A., \& Gardner, R. (2009). Teachers' motivation, classroom strategy use, students' motivation and second language achievement. Porta Linguarum, 12(1), 25-36.

Cheng, H. F., \& Dörnyei, Z. (2007). The use of motivational strategies in language instruction: The case of EFL teaching in Taiwan. Innovation in Language Learning and Teaching, 1(1), 153-174.

Csizér, K., \& Kormos, J. (2009). Learning experiences, selves and motivated learning behavior: A comparative analysis of structural models for Hungarian secondary and university learners of English. In Z. Dörnyei \& E. Ushioda (Eds.), Motivation, language identity and the L2 self (pp. 98-119). Bristol: Multilingual Matters.

Dörnyei, Z. (1998). Motivation in second and foreign language learning. Language Teaching, 31, 117-135. doi: 10.1017/S026144480001315X

Dörnyei, Z. (2001). Motivational strategies in the language classroom. Cambridge: Cambridge University Press. 
Dörnyei, Z. (2005). The psychology of the language learner: Individual differences in second language acquisition. New Jersey: Lawrence Erlbaum Associates.

Dörnyei, Z. (2006). Individual differences in second language acquisition. AILA Review, 19, 4268. doi: 10.1075/aila.19.05dor

Dörnyei, Z. (2007). Creating a motivating classroom environment. In J. Cummins \& C. Davison (Eds.), International handbook of English language teaching (Vol. 2, pp. 719-731). New York: Springer.

Dörnyei, Z. (2009). The L2 motivational self system. In Z. Dörnyei \& E. Ushioda (Eds.), Motivation, language identity and the L2 self (pp. 9-42). Bristol: Multilingual Matters.

Dörnyei, Z. \& Csizér, K. (1998). Ten commandments for motivating language learners: Results of an empirical study. Language Teaching Research, 2(3), 203-229. doi: $10.1177 / 136216889800200303$

Gardner, R. C., \& Lambert, W. E. (1959). Motivational variables in second language acquisition, Canadian Journal of Psychology, 13(4), 266-272.

Gardner, R. C., \& Tremblay, P. F. (1994). On motivation, research agendas, and theoretical frameworks. The Modern Language Journal, 78, 359-368. doi: 10.1111/j.15404781.1994.tb02050.x

Guilloteaux, M., \& Dörnyei, Z. (2008). Motivating language learners: A classroom-oriented investigation of the effects of motivational strategies on student motivation. TESOL Quarterly, 42(1), 55-77. doi: 10.1002/j.1545-7249.2008.tb00207.x

Hiromori, T. (2009). A process model of L2 learners' motivation: From the perspectives of general tendency and individual differences. System, 37, 313-321. doi:10.1016/j.system.2008.11.009

Kumaravadivelu, B. (2006). Understanding language teaching: From method to postmethod. Mahwah, NJ: Lawrence Erlbaum Associates.

MacIntyre, P. D., \& Blackie, R. A. (2012). Action control, motivated strategies, and integrative motivation as predictors of language learning affect and the intention to continue learning French. System, 40, 533-543. doi: 10.1016/j.system.2012.10.014

Moskovsky, C., Alrabai, F., Paolini, S., \& Ratcheva, S. (2012). The effect of teachers' motivational strategies on learners' motivation: A controlled investigation of second language acquisition. Language Learning, 63(1), 34-62. doi: 10.1111/j.14679922.2012.00717.x

Kormos, J., Kiddle, T., \& Csizér, K. (2011). Systems of goals, attitudes, and self-related beliefs in second-language-learning motivation. Applied Linguistics, 32(5), 495-516. doi:10.1093/applin/amr019

Oxford, R., \& Shearin, J. (1994). Language learning motivation: Expanding the theoretical framework. The Modern Language Journal, 78(1), 12-28. doi: 10.1111/j.15404781.1994.tb02011.x

Pallant, J. F. (2013). SPSS survival manual: A step by step guide to data analysis using SPSS (5 ${ }^{\text {th }}$ ed.). Berkshire: Open University Press.

Papi, M. (2010). The L2 motivational self system, L2 anxiety, and motivated behavior: A structural equation modeling approach. System, 38(3), 467-479. doi:10.1016/j.system.2010.06.011

Papi, M., \& Abdollahzadeh, E. (2011). Teacher motivational practice, student motivation, and possible L2 selves: An examination in the Iranian EFL context. Language Learning, 62(2), 571-592. doi: 10.1111/j.1467-9922.2011.00632.x 
Ruesch A., Bown, J., \& Dewey, D. P. (2012). Student and teacher perceptions of motivational strategies in the foreign language classroom. Innovation in Language Learning and Teaching, 6(1), 15-27. doi: 10.1080/17501229.2011.562510

Spolsky, B. (2000). Anniversary article; Language motivation revisited. Applied Linguistics, 21(2), 157-169. doi:10.1093/applin/21.2.157

Taguchi, T., Magid, M., \& Papi, M. (2009). The L2 motivational self system among Japanese, Chinese and Iranian learners of English: A comparative study. In Z. Dörnyei, \& E. Ushioda (Eds.), Motivation, language identity and the L2 self (pp. 66-97). Bristol, England: Multilingual Matters.

Weger, H. D. (2013). Examining English language learning motivation of adult international learners studying abroad in the US. RELC Journal, 44(1), 87-101. doi:10.1177/0033688212473272

\section{Copyrights}

Copyright for this article is retained by the author(s), with first publication rights granted to the Journal. This is an open-access article distributed under the terms and conditions of the Creative Commons Attribution license (CC BY-NC-ND) (http://creativecommons.org/licenses/by-nc-nd/4.0/). 